\title{
To Pay or Not To Pay: Guidelines for Prepayment
}

\author{
William F. Schenck
}

"... the curious incident of the dog in the nighttime."

"The dog did nothing in the nighttime."

"That was the curious incident," remarked Sherlock Holmes. ${ }^{1}$

Acquisitions work has its own curious incidents; publishers, who like the dog in the Holmes adventure, do nothing; they do not publish, let alone deliver announced books. Acquisitions librarians are aware of the problem; surely life would be easier if all books were published soon after they were announced. The problem is made much more severe, however, when publishers request that a library send payment for the material with an order. This themingly reasonable request often puts a library in a difficult situation. While there are very valid reasons for making prepayments, a library must be very careful to ensure the receipt of material for which it has paid. Unfortunately, some libraries in North Carolina and elsewhere have lost money in recent years by making advance payments for material which was never delivered. While this is a problem nationally, librarians in North Carolina should be aware of guidelines to use when making prepayments. This article will first examine theasons to make prepayments and why publishers often require them, and will then discuss possible safeguards. It will end with a specific discussion of one problem publisher and his products, emphasizing two current problematical projects.

today'se are many valid reasons to make prepayments. As a result of borrowed economic situation, and with the current high interest rates on increased money, the number of publishers who request prepayment has requested. Here are some of the major reasons why advance payment is

1. To obtain capital. Publishers can get interest free money by getting advance payment from libraries instead of banks. This method also allows a new firm to obtain capital to finance large projects which the more traditional funding sources might not be willing to support.

2. To save money. More and more publishers are requiring prepayment for all orders under a specific amount. For example, the American Library Association requires prepayment for all orders under $\$ 10.00$. By obtaining payment with the order the publisher saves the expense of invoicing.

3. To survey the market. By having advance paid orders, a publisher has a better idea of the market and can thus avoid printing too many copies.

4. To ensure payment. Usually libraries are good credit risks, as they eventually do pay. However, due to various bureaucratic procedures, 
a library may be very slow to pay its bills. Prepayment ensures rapid payment.

Libraries also have'valid reasons for making prepayments. Some of the reasons are

1. To acquire the material. In some cases there is no other way to acquire needed items. This is especially true of inexpensive materials published by associations and institutes.

2. To save money. Publishers will often set a lower price to encourage prepayments. On some larger projects it is also possible for a library to negotiate a discount if payment is sent with order. Prepayment also ensures delivery at that price. If a library waits until the material is actually available, it will often pay more. With inflation at about $10 \%$ a year, a library can estimate that the price of a project will increase at approximately that rate. The least a library should expect is the elimination of postage charges in return for payment.

3. To expend encumbered funds before established deadlines. A library may have ordered an expensive item only to discover that it is not yet available. It may be advantageous to pay for the material in the year the money has been allocated.

All of these reasons would be of little importance if libraries could always be sure of receiving material for which they had paid. Unfortunately, this sometimes does not happen. Firms which had the best of intentions find themselves going into bankruptcy; authors die, or price increases eliminate the projected market. Add to these problems the unscrupulous publisher who aggressively solicits advance payment without any plans to ever deliver ${ }^{2}$ and it is obvious that a library needs to establish a set of strict guidelines on prepay ments. Once the guidelines have been drawn up, they should be widely distributed, both to administrators and those on the staff responsible for processing orders and paying invoices. I have compiled the guidelines below from my own experience at the University of North Carolina at Chapel Hill and from those published by the Bookdealer - Library Relations Committee of ALA. ${ }^{3}$ By keeping these guidelines in mind, a library can prevent inappropriate prepayments while getting the most value for its money.

These guidelines should be used when judging larger prepayments. Each library should establish its own monetary limit. In many cases it is cheaper to send payment for inexpensive items than to spend time locating information on the publisher.

1. Know the publisher. While it is not possible to know all publishers, the name should be familiar or should at least be listed in basic sources.

2. Contact the publisher. If possible, call and speak to an officer of the company. Be leery of firms that operate only with a post office box and do not have a phone listing. ${ }^{4}$ (There are, of course, reputable firms which list only a post office box.)

3. Obtain specific information about the project. Ask for information of publishing schedules, previous projects published, credit references. or a Dun \& Bradstreet rating. Do not be afraid to ask for this informa tion; reputable publishers will gladly supply it. If it is possible, ask to received a copy of the first volume or microform produced. (This in 
itself is not proof of compilation, as some firms will produce Volume 1 for show and then never complete the set.)

4. Beware of "trendy" titles. One infamous publisher advertised sets with title such as The Encyclopedia of Women, Dictionary of Indians of North America.

5. Check with others on their experiences. Call other acquisitions librarians in the area. Write the Better Business Bureau or the Postal Service in the publisher's city. The best source of information is the Bookdealer-Library Relations Committee of ALA, a focal point for complaints on problem publishers. The Committee has also compiled a list of certain imprints (and addresses) which have caused difficulty for libraries and book sellers. ${ }^{5}$ Contact your book vendor. He or she will, from experience and contacts, have knowledge which can help you avoid making a mistake. You may wish to consider asking a dealer to actually make the prepayment. This should be done selectively, and you should avoid sending all prepayment requests to the same dealer.

6. Examine the announcements. Beware of flyers and brochures which look alike and carry similar information, but which may carry different addresses and imprints. Compare postmarks to see if they came from the same location.

7. Examine the price. It is legitimate to offer a lower price if an order is prepaid. Beware, however, of offers which have a great disparity between the two prices. You may want to set a limit on the amount which one person can authorize to prepay. At UNC-CH, the Head of Acquisitions must authorize any prepayment over $\$ 50.00$. Not only is this a double check, but it prevents an order and payment being made if the Head is absent. You might also consider either partial payment If or a performance bond. ${ }^{6}$

file of a prepayment is approved and made, the library should keep a special expected expive prepaid orders and claim any which are not received when the librd. The claim should be in the form of a letter or phone call and not on it rary's regular claim form.

need would be nice if, with the publicity surrounding prepayments and the however, guidelines, problem publishers would have disappeared. They are, imprints still alive, and even promoting "new" items in North Carolina. The operated which have presented the most problems are those believed to be team haved by Frank or Michael Gillie. ${ }^{7}$ The names which this father and son $\mathrm{B}_{0}$ kselle used present an abecedarian of imprints, ranging from Academic Bibliollors to Worldwide Reference Sources, with names in between like Press. Why Press, Knowledge Resources, Publishing Center, and Scholarly Michigan. While the addresses vary, many are located in St. Clair Shores,

Publis is important to note that these imprints often sound like other legitimate from thes. Also, this does not mean that you should not order publications Problems firms, just that you should be aware that other libraries have had avoided. 
There are two publications currently being advertised by publisher s $^{5}$ apparently affiliated with the Gillies. The first is directly aimed at North Carolina Libraries: North Carolina News and Index, published by the Publishers Sales Group, 610 S. Venice Blvd., Suite 4067, Venice, California ( $\mathrm{nO}$ telephone listing). The brochure for this publication promises a quarterly publication, and that it will "reprint and index the articles from hundreds 0 North Carolina newspapers." The second imprint is Knowledge Resources Inc., 3303 Harbor Blud., K-4, Costa Mesa, California (714-979-0211). This firm is offering various publications based on catalogs from the Library Congress. One example, from what is called the MARC Systems Division 0 Knowledge Resources, is MARC-Card Religion BL-BX, a classed list of all LC cards in those categories. Another project is the NUC, 1956-1977, an autho list master cumulation. According to the announcement, this will be available in either 300 printed volumes or on fiche. While prepayment is not required the svings is substantial; $53 \%$.

Before any library in the state invests money in these two specific public tions, they should investigate, based on the guidelines listed in this article. $B$ following the guidelines listed here and by using good common sense, libraries should be able to acquire all material needed at a reasonable cost and with minimum of risk.

William F. Schenck is acquisitions librarian, UNC-CH.

\section{REFERENCES}

1. From "Silver Blaze," The Memoirs of Sherlock Holmes, 1894.

2. For a tongue-in-cheek view of how a publisher would try to cheat libraries, see "How Succeed in Publishing Without Really Trying" by Charles Oznot (Pseud.) in Library Acqul tions: Practice and Theory, Vol. 1, 1979, pp. 7-10.

3. "The Prepayment Dilemma: A Consumer's Guide," American Libraries, Nov., 1977, pp. 5 ? 72 , is the source for all suggestions except the fourth.

4. Under the U.S. Freedom of Information Act, it is possible to obtain the name and address the holder of a post office box, if that box is used to conduct business. For details, see the U? Code, Section 552 title 5 , or consult your local postmaster.

5. For a copy write to the Chair, Bookdealer-Library Relations Committee, RTSD, Americ Library Association, 50 E. Huron St., Chicago, IL 60611.

6. Thomas M. Schmid, "How to Safeguard Money with Performance Bonds," Library Acqu" tions: Practice and Theory, Vol. 1, pp. 11-12, 1972.

7. For a list of these imprints, see FN 5. 


\title{
The Sandlapper Store, Inc.
}

\section{announces a new reprint edition of the}

\section{MILLS' ATLAS OF 1825}

In 1825 Robert Mills compiled an Atlas of the 28 Districts of South Carolina. There have been two modern reprints of this popular Atlas, both out of print.

This 1979 reprint edition has 28 District maps, a state map, an introduction by Charles E. Lee, Director of the S.C. Dept. of Archives \& History, and an index of names listed in the maps.

The maps are bound in a heavy-duty rich reddish brown leather-like binding with gold stamping. Only 6 of the maps are folded. The rest are 19 ' 'by 25 "'.

The complete Mills Atlas is $\$ 100.00$ is $\$ 15$.

Individual District maps are $\$ 10$ each and the state map (four-color)

\section{OTHER BOOKS OF INTEREST}

NINETY-SIX: THE STRUGGLE FOR THE S.C. BACK COUNTY by

Robert D. Bass

Dr, Bass is the S.C. Hall of Fame-1980 inductee

SWAMP FOX (The Story of Francis Marion) by

Robert D. Bass

GREEN DRAGON (The Story of Banastre Tarleton) by

Robert D. Bass

SOUTH CAROLINA: A SYNOPTIC HISTORY FOR LAYMEN by

Lewis P. Jones - newly revised

S. C. WOMEN - THEY DARED TO LEAD by

Idella Bodie

PLUM TREE LANE by Lodwick Hartley

(Former Head of English Department at N. C. State)

CARBINE: THE STORY OF DAVID MARSHALL WILLIAMS by Ross E. Beard, Jr.

THE EXECUTION OF ISAAC HAYNE by

Bavid K. Bowden

BATTLEGROUND OF FREEDOM: S. C. IN THE REVOLUTION

by Nat and Sam Hilborn

HOME BY THE RIVER by Archibald Rutledge

$\$ 12.50$

$\$ 7.50$

$\$ 6.95$

$\$ 7.95$

$\$ 9.95$

$\$ 9.95$

$\$ 12.50$

$\$ 9.95$

$\$ 12.95$

$\$ 10.00$

Complete listing Available. Write for free catalog.

Libraries receive a $10 \%$ discount.

\section{The Sandlapper Store, Inc.}

\author{
P. O. Box $841 \mathrm{~N}$
}

Lexington, S. C. 29072

803-359-6571 